\title{
Comparison of Two Soundscapes: An Opportunity to Assess the Dominance of Biophony Versus Anthropophony
}

\begin{abstract}
By Maria Paula Rey Baquero*, Clea Parcerisas*, Kerri D. Seger, Christina Perazio, Natalia Botero Acosta, Felipe Mesa, Andrea Luna-Acosta, Dick Botteldooren, and Elisabeth Debusschere (*equal first authors)
\end{abstract}

\section{SOUNDSCAPE DEFINED}

Sound travels further through water than light and is one reason why many marine animals use sound to communicate and gain information about their surroundings. Scientists collect recordings of these underwater sounds to gain information on species' habitat use, abundance, distribution, density, and behavior. In waters where visibility is severely limited or access is difficult or cost-intensive, passive acoustic monitoring is a particularly important technique for obtaining such biological information over space and time.

The "soundscape" of an ecosystem is defined as the characterization of all the acoustic sources present in a certain place (Wilford et al., 2021). A soundscape includes three fundamental sound source types (Figure 1): (1) anthropophony, or sounds associated with human activity; (2) biophony, or sounds produced by animals; and (3) geophony, or sounds generated by physical events such as waves, earthquakes, or rain (Pijanowski et al., 2011). Studying soundscapes can provide biological information for a specific habitat, which could then be linked to ecosystem health status and other bioindicators. This information can be used to monitor the habitat over time, allowing for rapid detection of habitat degradation, such as in response to human-driven events.

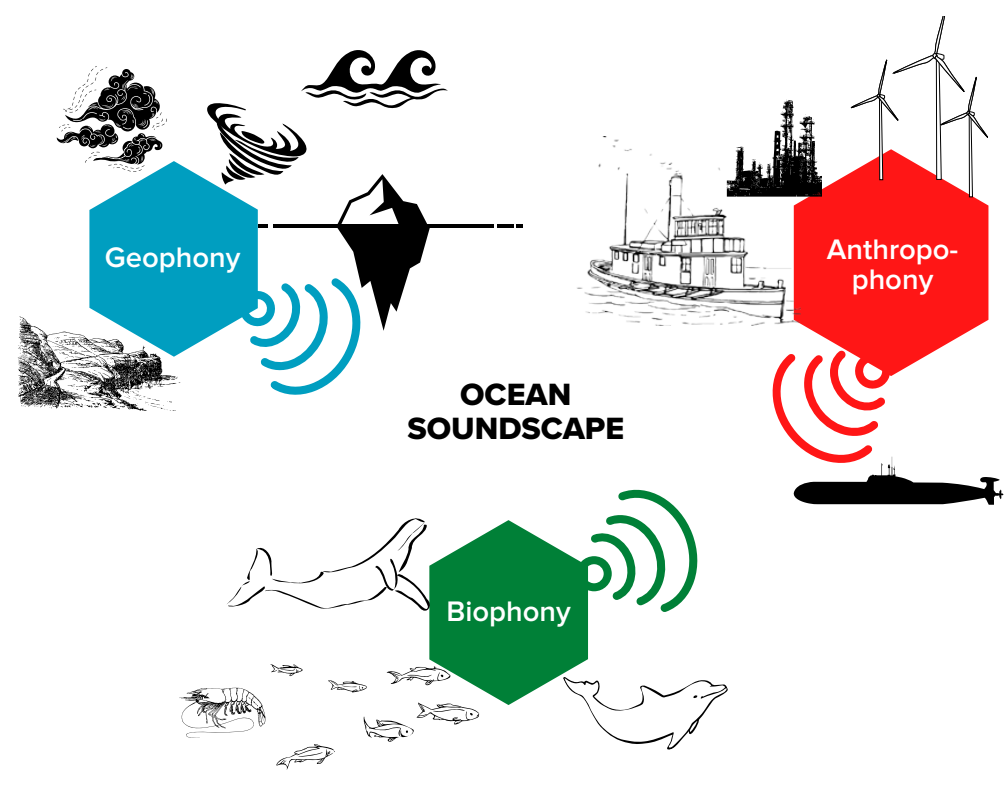

FIGURE 1. Examples of the three sources of an oceanic soundscape: anthropophony, biophony, and geophony.

\section{SOUNDSCAPE DATA ACQUISITION}

Acoustic recordings can be collected using devices that are either fixed to the ocean floor or floating/navigating in the water column; by stations cabled to a land-based laboratory; or by instruments towed from boats (i.e., hydrophones) or attached to animals (i.e., bio-loggers). New technologies permit long deployments (months) that generate large amounts of acoustic data. Analyses of these data are very labor and time intensive, so automation is highly desirable.

\section{SOUNDSCAPE ANALYSES}

Because the study of underwater soundscapes is relatively new, there is not yet a standardized way of processing acoustic data (Wilford et al., 2021). Thus, given the variety of instruments, mooring types, and deployment settings available, it can be challenging to compare results between different data sets. However, some initiatives, like the International Quiet Ocean Experiment (IQOE), are creating standards for underwater sound processing.

When analyzing acoustic habitats, different approaches can be considered. Common examples include the detection and quantification of specific events or the calculation of acoustic indices, which are summary statistics that describe the distribution of acoustic energy and can sometimes be correlated with certain biological or ecological habitat properties. Apart from classical acoustic indices, sound ecological indices could reveal the status of marine ecosystems, but they require previous knowledge about each sound type and its characteristics. One common approach to visualizing the soundscape is to use a spectrogram, a visual representation of a sound's intensity and frequency over time. A spectrogram allows identification of interesting acoustic events and their timing, even for sounds outside the human hearing range.

\section{NOISE POLLUTION}

Over the last many decades, human activities at sea such as pile driving, dredging, or shipping have increased, contributing to and sometimes dominating underwater sound levels. When anthropophony masks biophony, marine animals that rely on sound to detect predators or prey, to find or communicate with mates or offspring, and/or to navigate can be harmed (Duarte et al., 2021). Thus, it is important 
to describe and record the soundscapes of places that are currently less and more disturbed to quantify current noise levels. Knowledge of these "baselines" will enable us to measure additional human-driven degradation to the oceanic soundscape and the resulting impact on marine life.

Jacques Cousteau's first impression of the ocean was that it was silent. We now know it has always been filled with natural sounds. In 2008, the European Marine Strategy Framework Directive (MSFD) established that low underwater sound levels are one descriptor of a Good Environmental Status (GES) (MSFD 2008/56/EC), even though there is still no common description of an acoustic GES. On the other side of the Atlantic Ocean, and in the Southern Hemisphere, Colombia's National Environmental Licensing Authority (ANLA), in charge of environmental regulations for infrastructure projects, stipulated in articles 2 and 3 of decree 3573 that licenses for megaprojects, such as port construction, must be approved by ANLA, which is also responsible for monitoring environmental implications.

\section{CASE STUDIES}

Here, we describe two study regions with vastly different soundscapes, characterized by extremely different shipping densities (Figure 2). The first study region, the Gulf of Tribugá, Colombia, is "less disturbed" by undersea noise (closest to pristine). It serves as a general marine soundscape baseline for comparison with possible future disturbances from port construction and operation. By contrast, the second study region, the Belgian part of the North Sea (BPNS) is located in a "more disturbed" area of very exploited shallow waters. Its baseline is being used to monitor the effects of noise reduction policies. We chose October 16, 2020, at 12:00 until October 17, 2020, at 07:30 (local time) as the day for our soundscape comparison. Our hypothesis is that biophony dominates the Gulf of Tribugá while anthropophony dominates the BPNS.

\section{Gulf of Tribugá}

The main goals of the PHySIColombia Project were to identify which sound sources exist in the Gulf of Tribugá (Figures 2a and 3); to measure the contributions of sounds from small boats, humpback whales, fish, dolphins, and storms/tides; and to establish the cycles for each source (Rey-Baquero et al., 2021). One of the rainiest areas on Earth, Tribugá boasts high biological diversity. Due to its high ecological value, it is a newly designated Hope Spot (a) Gulf of Tribugá, Colombia

(b) Belgian Part of the North Sea

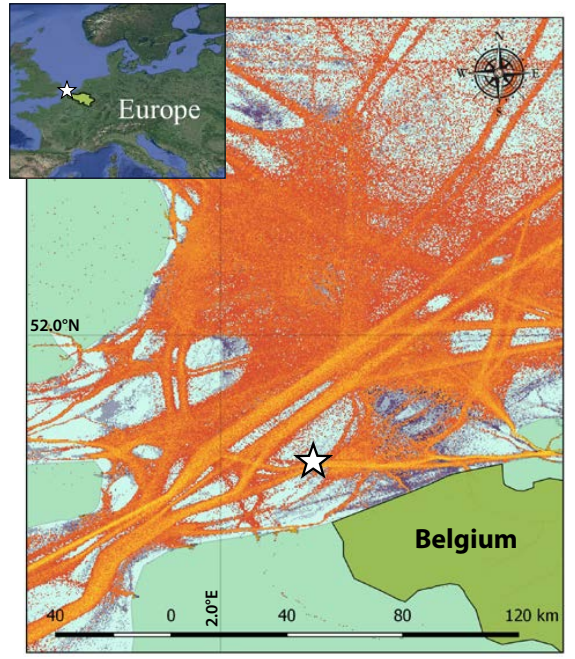

15 to 2020. (a) Study area in the Gulf of Tribugá, which is in the department of Chocó, Colombia. The star indicates the location of the acoustic recorder in Morro Mico. (b) Study area located off the coast of Belgium. The star indicates the location of the acoustic recorder. (an ecologically unique area of the ocean designated for protection). This area currently contains no shipping lanes, so boat noise is generated only from small-scale ecotourism and artisanal fishing. It is part of the breeding grounds for humpback whale (Megaptera novaeangliae) Stock G, a species whose survival relies on acoustic communication. The longest monitored deployment site (from 2018 to 2021) is Morro Mico (552'10.1"N, 77¹8'40.7'W), in the north of the Gulf just south of Utría National Park, about $0.5 \mathrm{~km}$ from the coast. Data were collected at $25 \mathrm{~m}$ depth using an ecological acoustic recorder (Oceanwide Science Institute) programmed to record for 10 minutes every half hour at $15.625 \mathrm{kHz}$ sampling rate. 


\section{Belgian Part of the North Sea}

As a part of the Belgian LifeWatch project, an acoustic network was deployed that records continuously in different locations of the BPNS, one of the busiest ocean areas in the world. This shallow sea is characterized by sand banks and a wide variety of sediment that hosts five benthic communities.

The aim of this network is to measure underwater sound across benthic habitats. The lack of historical data prohibits defining an unimpacted soundscape baseline. The location for the site used to compare with the Gulf of Tribugá is the Westhinder shipwreck $\left(51^{\circ} 22^{\prime} 52.2^{\prime \prime} \mathrm{N}, 2^{\circ} 27^{\prime} 9.72^{\prime \prime} \mathrm{E}\right.$; Figures $2 b$ and 4 ), which is next to an anchor zone for commercial ships and close to a shipping lane. Therefore, shipping and other anthropophony constitute an overwhelmingly dominant ocean sound source. It is also populated with harbor porpoises (Phocoena phocoena), but their echolocation frequency is too high for the recorder used, so they cannot be seen in the acquired data. Data were collected with a SoundTrap $300 \mathrm{HF}$ (Ocean Instruments) attached to a tripod at $1 \mathrm{~m}$ above the sea bottom at $96 \mathrm{kHz}$ sampling rate, recording continuously. It was $32 \mathrm{~m}$ deep and about $30 \mathrm{~km}$ from the coastline.

\section{SPECTROGRAM VISUALIZATION}

We identified different sounds using spectrograms generated by Raven Pro 1.6 software (Figure 5). Marking the spectrograms manually when each sound type occurred allowed us to determine the schedules on which animals, natural events, and human-made noises operated. The largest contribution to the Gulf Tribugá soundscape was from singing humpback whales, then shrimp, and finally fish. Anthropophony was primarily from small boats, but occasionally from one or two larger shrimping boats. The loudest geophony sounds came from rain and wind, while the sloshing of the tide and crashing of waves onshore commonly existed in the background.

In contrast, anthropogenic noise dominates the BPNS soundscape. The identified sounds were generated by large ships, probably commercial or fishing. Another identified sound is possibly dredging or trawling, which is concentrated at about $1 \mathrm{kHz}$ or below and is constant and prolonged.

\section{SPECTRAL PROBABILITY DENSITY COMPARISON}

To compare the soundscapes of both locations, we computed the spectral probability density (SPD) of each location using pypam (https://github.com/lifewatch/pypam). SPD is useful for computing the statistical distribution of underwater noise levels across the frequency spectrum (Merchant et al., 2013). To compute the SPDs, the audio files were divided into one-minute samples. Frequency distribution and the probability of each frequency appearing at a certain sound level (from 20 to $140 \mathrm{~dB}$ re $1 \mu \mathrm{Pa}$ ) were computed, and both sites were processed to remove the direct current (DC) electrical noise generated by the instruments. The data from the BPNS location were downsampled to match the sampling rate used in Tribugá so that the frequency and time resolution of both SPD computations would match.

The $11^{\text {st }}, 10^{\text {th }}, 50^{\text {th }}, 90^{\text {th }}$, and $99^{\text {th }}$ percentiles of the SPD represent the intensities and contributions of sounds in the soundscape. The $1^{\text {st }}$ percentile represents sounds that occur $99 \%$ of the time but are low intensity, and the
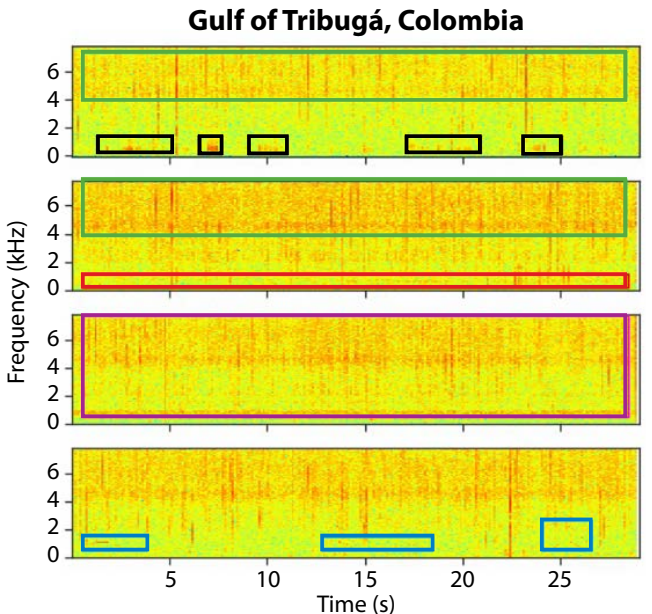

Belgian Part of the North Sea

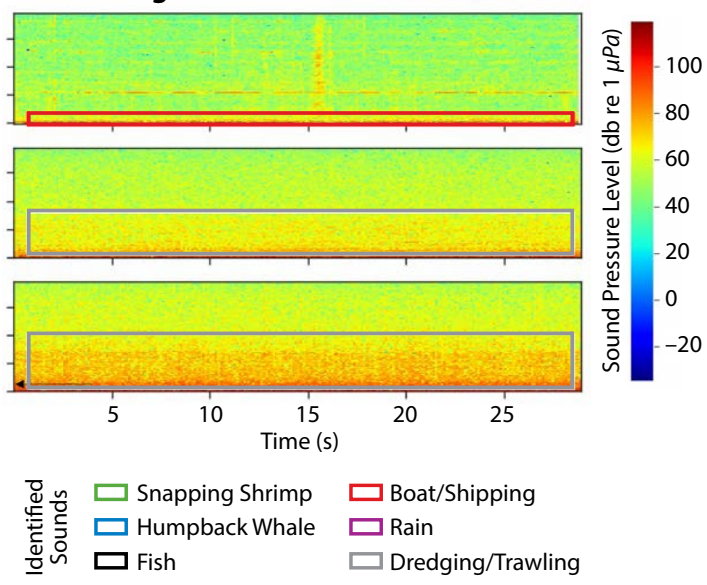

FIGURE 5. Spectrogram visualization of identified sounds in the Gulf of Tribugá and the Belgian part of the North Sea (BPNS) soundscapes. Color boxes show each type of sound's bandwidth. NFFT is 4096. Snapping shrimp (green boxes) sounds are roughly above $4 \mathrm{kHz}$. Humpback whale song units (blue boxes) are between about $50 \mathrm{~Hz}$ and $4 \mathrm{kHz}$. Fish sounds (black boxes) are usually below $1 \mathrm{kHz}$. The fundamental frequencies of boat engines are also usually up to about $1 \mathrm{kHz}$ (red boxes). Raindrops (purple box in spectrogram second from bottom at left) can be $1 \mathrm{kHz}$ to many $\mathrm{kHz}$. Noises associated with dredging or trawling (gray boxes) can reach up to $4 \mathrm{kHz}$. 
FIGURE 6. Spectral probability density of the two locations. Oneminute window of one day, no overlap, NFFT 4096, histogram bin size of $1 \mathrm{~dB}$ re $1 \mu \mathrm{Pa}$. Boxes with dashed lines show possible boat sounds, continuous lines indicate humpback whales sounds, and dash-dot lines show shrimp sounds. Overlap in frequency with the sound of the humpback is an example of masking biophony.

$99^{\text {th }}$ percentile represents the loudest sounds, which occur only $1 \%$ of the time. Depending on the soundscape, each percentile can represent different sound sources.

Biophony dominates Tribugá's soundscape: the $1^{\text {st }}$ percentile represents the sounds of snapping shrimp (sound energy above $4,000 \mathrm{~Hz}$ ); the humpback song is represented by the $10^{\text {th }}$ and $50^{\text {th }}$ percentiles, especially if there are several whales singing at once. One common high-energy frequency band in song $(\sim 300 \mathrm{~Hz})$ is visible as a less evident peak (when there are fewer singers) in the $90^{\text {th }}$ percentile. Another peak above $1,000 \mathrm{~Hz}$ could represent another band in humpback whale song, but because it is only in the $90^{\text {th }}$ percentile for this day, it likely is due to rain (Figure 6). The $99^{\text {th }}$ percentile has a predominant peak around $300 \mathrm{~Hz}$, and there are several other peaks between $50 \mathrm{~Hz}$ and $1,000 \mathrm{~Hz}$ that represent bands of noise from small whale-watching and fishing boats that speed by Morro Mico quickly.

In the BPNS's SPD, there is a clear peak between $20 \mathrm{~Hz}$ and $300 \mathrm{~Hz}$, which is known to be the frequency band for shipping noise. Compared to Tribugá, ship noise is present for longer durations in the BPNS. Biophony present in the BPNS is mostly masked by anthropophony, and the contribution of marine animals to the soundscape in the BPNS is less frequent than anthropophony, so it is not obviously represented in the SPD. In addition, recorded sound levels are generally louder in the BPNS than in Tribugá (Figure 6). The loudest sounds in the BPNS are lower in frequency, while in Tribugá the higher frequencies are louder. Because sound sources are more infrequent in Tribugá (i.e., no shipping lane exists to create a constant band of noise), it has greater variability in frequency and loudness, which correlates with some studies that link biological sounds to greater variation of sounds in frequency and time (Wilford et al., 2021).

\section{CONCLUSIONS AND PERSPECTIVES}

By first establishing acoustic baselines in less and more noisy ocean regions, monitoring soundscapes over time can be a cost-effective method for assessing the health of marine ecosystems. Some scientists are developing acoustic indices that would link acoustic features to biodiversity or other biological indicators (Wilford et al., 2021). Few standards exist for sensor deployment configuration, making ecosystem comparisons challenging or not feasible, and no global acoustic indicator yet exists. However, various groups are working to standardize marine acoustic

\section{SPECTRAL PROBABILITY DENSITY}

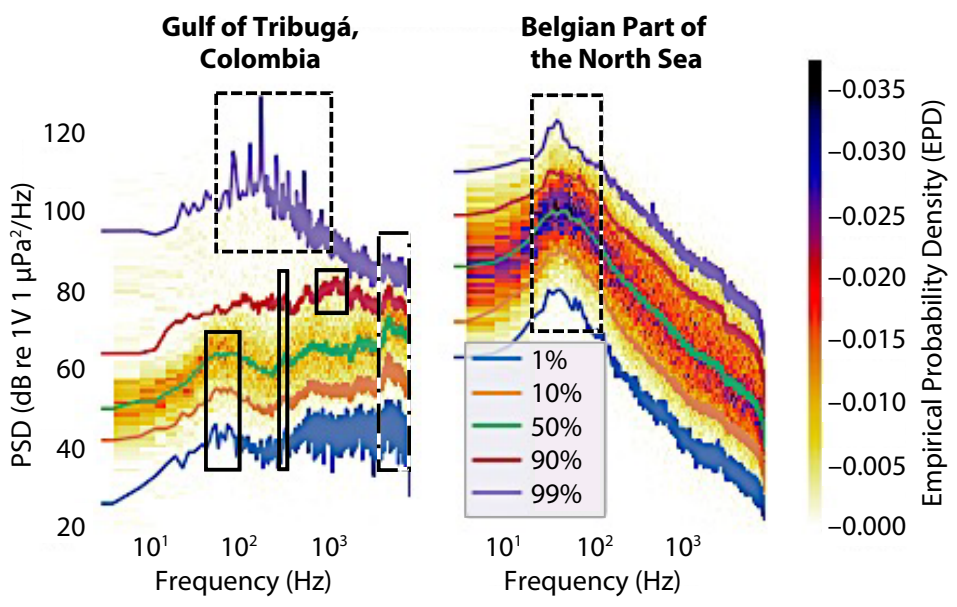

data acquisition and to develop a more general approach to establishing different ecosystems' soundscapes. How long or how often the recorder is active also influences data analysis, so it is often not possible to compare different time periods. Because many studies focus on a single region and have budget constraints, data often come from one type of environment and deployment configuration. Several recorders spaced at intervals could capture soundscapes in a single area with varying seafloor topography or differing sediment types.

Biophony dominated the Gulf of Tribugá, while anthropophony dominated the BPNS and masked any biophony. Our analysis demonstrated that different sources drove each soundscape. If the sound sources are known, SPD can be interpreted by specialists to describe the soundscape, but unknown sources remain a limitation for soundscape studies.

\section{REFERENCES}

Duarte, C.M., L. Chapuis, S.P. Collin, D.P. Costa, R.P. Devassy, V.M. Eguiluz, C. Erbe, T.A.C. Gordon, B.S. Halpern, H.R. Harding, and others. 2021. The soundscape of the Anthropocene ocean. Science 371:eaba4658, https://doi.org/10.1126/science.aba4658.

Merchant, N.D., T.R. Barton, P.M. Thompson, E. Pirotta, D.T. Dakin, and J. Dorocicz. 2013. Spectral probability density as a tool for ambient noise analysis. Journal of the Acoustical Society of America 133:EL262EL267, https://doi.org/10.1121/1.4794934.

Pijanowski, B.C., L.J. Villanueva-Rivera, S.L. Dumyahn, A. Farina, B.L. Krause, B.M. Napoletano, S.H. Gage, and N. Pieretti. 2011. Soundscape ecology: The science of sound in the landscape. BioScience 61:203-216, https://doi.org/10.1525/bio.2011.61.3.6.

Rey-Baquero, M.P., L.V. Huertas-Amaya, K.D. Seger, N. Botero-Acosta, A. Luna-Acosta, C.E. Perazio, J.K. Boyle, S. Rosenthal, and A.C. Vallejo. 2021. Understanding effects of whale-watching vessel noise on humpback whale song in the North Pacific coast of Colombia with propagation models of masking and acoustic data observations. Frontiers in Marine Science 8:623724, https://doi.org/10.3389/fmars.2021.623724.

Wilford, D.C., J.L. Miksis-Olds, S.B. Martin, D.R. Howard, K. Lowell, A.P. Lyons, and M.J. Smith. 2021. Quantitative soundscape analysis to understand multidimensional features. Frontiers in Marine Science 8:672336, https://doi.org/10.3389/fmars.2021.672336.

ARTICLE DOI: https://doi.org/10.5670/oceanog.2021.supplement.02-24 


\section{AUTHORS}

Maria Paula Rey Baquero* (rey_m@javeriana.edu.co), Departamento de Ecología y Territorio, Facultad deEstudios Ambientales y Rurales, Pontificia Universidad Javeriana, Colombia. Clea Parcerisas* (clea.parcerisas@vliz.be), Flanders Marine Institute, Belgium, and WAVES Department, Ghent University, Belgium. Kerri D. Seger, Applied Ocean Sciences, USA, and Fundación Macuáticos Colombia, Colombia. Christina Perazio, Neural and Cognitive Plasticity Lab, Evolution, Ecology, \& Behavior Program, State University of New York at Buffalo, USA, and Fundación Macuáticos Colombia, Colombia. Natalia Botero Acosta, Fundación Macuáticos Colombia, Colombia. Felipe Mesa, Expedición Tribugá, Colombia. Andrea Luna-Acosta, Departamento de Ecología y Territorio,

Facultad de Estudios Ambientales y Rurales, Pontificia Universidad Javeriana, Colombia. Dick Botteldooren, WAVES Department, Ghent University, Belgium. Elisabeth Debusschere, Flanders Marine Institute, Belgium.

\section{ARTICLE CITATION}

Rey Baquero, M.P., C. Parcerisas, K.D. Seger, C. Perazio, N. Botero Acosta, F. Mesa, A. Luna-Acosta, D. Botteldooren, and E. Debusschere. 2021. Comparison of two soundscapes: An opportunity to assess the dominance of biophony versus anthropophony. Pp. 62-65 in Frontiers in Ocean Observing: Documenting Ecosystems, Understanding Environmental Changes, Forecasting Hazards. E.S. Kappel, S.K. Juniper, S. Seeyave, E. Smith, and M. Visbeck, eds, A Supplement to Oceanography 34(4), https://doi.org/10.5670/oceanog.2021.supplement.02-24.

\section{COPYRIGHT \& USAGE}

This is an open access article made available under the terms of the Creative Commons Attribution 4.0 International License (https://creativecommons.org/ licenses/by/4.0/), which permits use, sharing, adaptation, distribution, and reproduction in any medium or format as long as users cite the materials appropriately, provide a link to the Creative Commons license, and indicate the changes that were made to the original content. 